\title{
REVISITANDO UMA DEFINIÇÃO DE TERCEIRIZAÇÃO
}

\author{
Sávio Cavalcante* \\ Paula Marcelino * *
}

\begin{abstract}
No ano de 2012 defendemos uma definição: terceirização é todo processo de contratação de trabalhadores por empresa interposta, cujo objetivo último é a redução de custos com a força de trabalho e/ou a externalização dos conflitos trabalhistas. Com o presente artigo pretendemos afirmar a validade dessa definição à luz dos acontecimentos jurídico-políticos situados no Brasil e que são posteriores àquela publicação, quais sejam: processos julgados pelo Supremo Tribunal Federal (STF) até o presente e as leis que liberaram a terceirização de maneira irrestrita, promulgadas em 2017 (leis 13.429 e 13.467). Também explicitaremos as raízes teóricas da nossa definição. Defenderemos a tese de que aquela definição permanece válida e operacional. A pesquisa foi feita por meio de análise documental (textos produzidos e publicados em imprensa comercial, sindical e independente, documentos do Supremo Tribunal Federal e revisão bibliográfica.
\end{abstract}

Palavras-chave: Terceirização. Subcontratação. Trabalho. Brasil.

\section{INTRODUÇÃO}

De 2012, ano em que publicamos nosso texto "Por uma definição de terceirização", até os dias de hoje, o Brasil passou por mudanças drásticas; e para pior, ao menos do ponto de vista das classes trabalhadoras. Houve um golpe jurídico-parlamentar sobre uma presidenta democraticamente eleita, Dilma Rousseff, em 2016 (Boito Jr., 2018); uma reforma trabalhista profundamente danosa para os direitos dos trabalhadores foi aprovada em dezembro de 2017 (Galvão et al., 2017); ocorreu a eleição de um governo federal de extrema direita, Jair Bolsonaro, em 2018, e uma reforma da previdência social, que também reduziu direitos, foi implementada em novembro de 2019 (Fagnani, 2019).

* Universidade Estadual de Campinas (Unicamp). Instituto de Filosofia e Ciências Humanas (IFCH). Departamento de Sociologia.

Cora Coralina, 100. Cidade Universitária. Cep: 13083-896. Campinas - São Paulo - Brasil. saviomc@unicamp.br https://orcid.org/0000-0002-8496-5357

* * Universidade de São Paulo (USP). Faculdade de Filosofia, Letras e Ciências Humanas (FFLCH). Departamento de Sociologia (DS).

Avenida Luciano Gualberto, 315. Cidade Universitária. Butantã. Cep: 05508-010. São Paulo - São Paulo - Brasil. prpmarcelino@gmail.com

https://orcid.org/0000-0003-0692-1129
Do ponto de vista da regulamentação da terceirização, o período foi igualmente marcado por retrocessos, sendo o principal deles a aprovação das leis 13.429/17 e 13.467/17 que permitem a terceirização em qualquer setor das empresas, seja ele destinado ou não àquela que é considerada a atividade-fim, - o objetivo da empresa, registrado em seu contrato social - de cada uma delas. Ambas as leis foram legitimadas por posições da maioria do STF de que a nova norma, embora alterasse quase três décadas de entendimento do Tribunal Superior do Trabalho, não se caracterizava como inconstitucional.

Por mais experimentadas que sejam as classes trabalhadoras brasileiras com a terceirização, por mais presente que essa estratégia de contratação esteja no mercado de trabalho brasileiro, na atividade cotidiana de parte expressiva dos operadores do Direito e nas pesquisas de diversas áreas do conhecimento - como atesta a pluralidade de origens dos autores deste dossiê - acreditamos que ainda há muita confusão no que concerne à sua definição. E essa confusão ajuda a tornar mais obscuro o caminho para enfrentar os efeitos deletérios da terceirização para os trabalhadores 
e as trabalhadoras. Por isso, neste artigo aprofundaremos o debate que nos levou à definição de terceirização como “(...) todo processo de contratação de trabalhadores por empresa interposta, cujo objetivo último é a redução de custos com a força de trabalho e/ou a externalização dos conflitos trabalhistas" (Marcelino e Cavalcante, 2012, p. 338). A forma como essa definição simples e sintética foi construída e a argumentação para defendê-la, o leitor poderá encontrar naquele artigo. Neste que agora escrevemos, nosso objetivo é duplo: apresentar a orientação teórica que guiou aquela definição e testar, à luz dos acontecimentos jurídico-político posteriores ao ano de 2012, a sua pertinência, precisão e capacidade explicativa.

\section{ACERTANDO AS CONTAS COM A TEORIA}

A definição de terceirização que propusemos em 2012 tinha um fundamento teórico que não estava explícito naquele texto e que pretendemos expor aqui. São dois debates, fundamentalmente: a) como nossa definição se posiciona em relação à teoria do valor marxista, que salienta a subsunção da criação de valores de uso ao processo geral da valorização do capital e b) a importância da estrutura jurídico-política para entender a conjuntura ampla e os fenômenos sociais em específico. ปิ Comecemos pelas repercussões da teoria do กิ valor sobre o fenômeno da terceirização.

O principal limite conceitual que identificamos na bibliografia que tratava o tema da terceirização e que expusemos no artigo de ¿. 2012 era expresso no que chamamos o "dilema Æे da dualidade”. Em linhas gerais, dizia respeito

à tendência dos estudos que trabalhavam no seguinte registro: a terceirização faria parte de um processo mais amplo de desverticalização e busca de aprimoramento da especialização que, em si, poderia acarretar tanto melhorias nos processos produtivos quanto consequências negativas para as condições de trabalho.
Ainda que parte importante da literatura priorizasse a tendência de precarização do ponto de vista dos trabalhadores, o pressuposto continuava sendo de que a ampliação do uso da terceirização pelas empresas estava inserida num movimento maior de acentuação da divisão do trabalho e na busca pela especialização de serviços e aumento da produtividade, o que seria a parte "positiva" desse processo. Não se identificavam, nesse sentido, diferenças qualitativas entre formas gerais de subcontratação ou prestação de serviços entre empresas, de um lado, e a terceirização em si, de outro. Foi no intuito de superar esse limite que propusemos uma definição de terceirização que deliberadamente abandonava a problemática da divisão do trabalho em geral entre empresas - orientada, em última instância, para a compreensão de como se produzem valores de uso, ou seja, as mercadorias, os produtos físicos ou os serviços - e, no seu lugar, nos valemos da problemática da valorização do capital que, tal como nos apontou Marx (2001 [1867]), obriga a que os capitalistas pressionem "para baixo" as condições de venda da força de trabalho.

Mas, se a pressão geral da valorização do capital é pela diminuição das proteções e garantias vistas pelo empresariado como "exógenas" (seja pela pressão de acordos coletivos ou por legislação), ao contrato de trabalho, qual seria a determinação específica que diferencia a terceirização de outras formas de provocar esse rebaixamento dos custos com trabalho vivo, com os trabalhadores? Em nossa definição, a existência de uma empresa interposta para a qual se externaliza a contratação - e com ela, parte importante dos custos trabalhistas, além dos conflitos advindos do vínculo de trabalho e de sua exploração - é a dimensão decisiva que permite diferenciar a terceirização de outras formas de subcontratação ou mesmo de dissimulação da condição de assalariamento pelo uso de "autônomos" - aspecto importante do debate que se acentua com a proliferação contemporânea de contratação de trabalho por plataformas, como indicaremos posteriormente. 
Em suma, introduzir uma nova pessoa jurídica entre a empresa que controla efetivamente o processo de trabalho e os trabalhadores é, simultaneamente, uma importante estratégia econômica e política. Econômica, porque amplia fortemente as possibilidades de renegociações constantes dos custos com força de trabalho ao sabor das oscilações do mercado e das pressões advindas de retorno de investimentos com o predomínio das finanças no capitalismo neoliberal (Paulani, 2016). Política, porque preserva o controle técnico sobre o processo de trabalho, externalizando os incontornáveis conflitos trabalhistas resultantes da pressão econômica por rebaixamento de custos.

Retomando a problemática marxista do valor (Saad Filho, 2011), nossa definição, portanto, abarca a necessidade permanente, no modo de produção capitalista, de se encontrar mecanismos para acentuar a exploração do trabalho abstrato, o que deixa em segundo plano (subsumida) a discussão técnica a respeito da conformação específica - por exemplo, a adoção ou não da terceirização - da produção de valores de uso. ${ }^{1}$ Sabe-se que a atividade-fim da empresa capitalista é valorizar o valor; e a substância do valor é o trabalho abstrato socialmente necessário cuja grandeza se mensura por unidades de tempo. Como afirmamos no artigo de 2012, ao privilegiar a dimensão da especialização de tarefas e a divisão do trabalho, a maioria das análises sobre terceirização, bem como suas definições correntes, explicitamente ou não, acabam por inverter o sentido material e objetivo da forma capitalista de exploração: “o processo de valorização aparece como subordinado ao processo de trabalho, quando é o inverso que guia a ação das empresas, isto é, é a valorização que subsume o processo de trabalho" (Marcelino e Cavalcante, 2012, p. 339).

${ }^{1}$ Segundo Saad Filho (2011, p. 24): “(...) no capitalismo, o trabalho geralmente tem uma dupla determinação; ele é concreto e, também, abstrato. Enquanto trabalho concreto, ele é uma atividade transformadora; enquanto trabalho abstrato, ele é subordinado por uma forma social específica, ou ele existe através dessa forma. O trabalho abstrato predomina sobre o trabalho concreto porque a performance do último geralmente depende da extração de mais-valia, em vez de, por exemplo, depender da necessidade do produto".
A validação empírica mais explícita desta tese estava se formando na conjuntura mesma em que redigíamos o citado artigo: o discurso das organizações patronais e das bancadas comprometidas com os interesses empresariais já abandonavam, àquela altura, a justificativa da importância da terceirização para atividades-meio e, com isso, o fato de as empresas terem condições de focar na sua atividade-fim. Todo o arcabouço ideológico construído pela literatura do campo da administração de empresas na década de 1990 começou a ser dissolvido em nome de outro princípio: a defesa do princípio constitucional da "livre iniciativa", com a recusa de qualquer forma de responsabilidade sobre os terceirizados. ${ }^{2}$ A Audiência Pública no TST, realizada em 2011, já sinalizava o distanciamento dos representantes das organizações empresariais em relação aos argumentos dos pesquisadores liberais do campo da administração da década de $1990 .{ }^{3}$ Nos anos seguintes, especialmente com a conjuntura política do Golpe de 2016, esse movimento das organizações empresariais se fortaleceu e, além de ser atendido pelas

${ }^{2}$ No início de 2010, por exemplo, quando o então Ministério do Trabalho apresentou proposta de regulamentação mais restritiva para a terceirização, Vander Morales, presidente da Asserttem (Associação Brasileira das Empresas de Serviços Terceirizáveis e de Trabalho Temporário), argumentou: "O texto é claramente corporativista. No projeto, obriga-se que a remuneração do terceirizado siga convenção ou acordo coletivo de trabalho, celebrados entre empresa tomadora de serviços e sindicato da categoria profissional preponderante. E vai além ao exigir que, caso essa remuneração seja menor, a empresa prestadora de serviços complementará a diferença, sob a forma de abono. $\mathrm{O}$ retrocesso prossegue: veda a contratação de serviços em atividades fins. A discussão é arcaica. Quem, com clareza, pode no mundo de hoje distinguir o que é atividade fim de atividade meio em uma empresa?" Ao fim, Morales antecipa o que viria de fato a ocorrer após o fim do ciclo dos governos petistas: "Dificilmente empresas do exterior com interesse em investir no Brasil concretizarão suas intenções caso a inviabilidade de terceirização no Brasil se transmute em letra de lei. Aliás, há mais de 11 anos está em discussão no Congresso o projeto 4.302/98, objeto de exaustivos debates e muito consenso" (Morales, 2010, s/p.). Em 2015, a Confederação Nacional das Indústrias elegeu, por meio de sua "Agenda Legislativa", o fim das restrições legais à terceirização irrestrita como uma de suas prioridades (https://agencia.fpagropecuaria.org.br/2015/03/23/ cni-prioriza-terceirizacao-na-agenda-legislativa).

${ }^{3}$ Uma expressão importante, nesse sentido, já em 2014, foi o Recurso Extraordinário com Agravo (ARE) a pedido da Contax S.A e Associação Brasileira de Telesserviços e Federação Brasileira de Telecomunicações, que alegava a inconstitucionalidade da Súmula 331 do TST, a qual proibia terceirização em atividades-fim. O argumento foi posteriormente acolhido pela maioria do STF (Biavaschi et al., 2021). 
mudanças legislativas em 2017, foi respaldado por decisões do Supremo Tribunal Federal (STF) que, como discutiremos a seguir, fizeram prevalecer o princípio de livre iniciativa em detrimento dos direitos do trabalho.

Essas mudanças nos levam ao segundo ponto teórico-analítico que indicamos no início desta seção, expresso na tentativa de resposta para a seguinte pergunta: a forma legislativa da terceirização deve ou não ter papel central na definição do fenômeno? Nossa resposta para essa pergunta já foi dada na definição de 2012, e ela é positiva. Ou seja, na nossa definição de terceirização é fundamental o entendimento do lugar jurídico ocupado pelo trabalhador e pelas empresas na relação empregatícia. Mas, o que justifica, teoricamente, essa resposta positiva?

Existe uma tradição teórica dentro do marxismo para a qual a estrutura jurídico-política desempenha, em níveis diversos de abstração, papel determinante na conformação dos fenômenos sociais. Para essa tradição, os acontecimentos naquele que seria considerado o campo da superestrutura, ou seja, os acontecimentos políticos relacionados ao poder e à configuração do Estado (Direito e burocratis$\mathrm{mo}^{4}$ ) formam uma totalidade com a infraestrutura econômica. A superestrutura juridico-política, em um modo de produção qualquer, tem a função de reproduzir a infraestrutura econômica desse modo de produção (Boito Jr., $\overrightarrow{\widehat{~}}$ 2007). Tal tradição teórica foi inaugurada por Louis Althusser e tem desenvolvimento, entre outros, na teoria política de Nicos Poulantzas ฮิ (1978, 2019). É essa tradição teórica que inforЭิ ma a nossa definição de terceirização.

$\dot{2} \quad$ Dois exemplos do impacto da estrutura ঙ্ jurídico-política na conformação de fenôme-

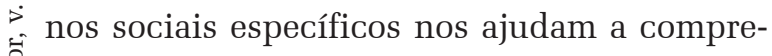
ender melhor a importância que estamos dando aos aspectos jurídico-políticos da terceiriza-

${ }^{4} \mathrm{O}$ conceito de burocratismo refere-se ao fato de, no Estado de tipo burguês, capitalista, a burocracia ser formalmente aberta aos indivíduos de todas as classes sociais e ser organizado, a princípio, por critérios de competência e mérito (Boito Jr., 2007). ção: o nascimento do sindicalismo como forma de organização dos trabalhadores e a análise da cidadania em sociedades capitalistas. O primeiro tema foi tratado por Armando Boito Jr. (2007) e o segundo, por Décio Saes (2003). No primeiro, Boito Jr. (2007) defende a tese de que apenas com o advento do capitalismo o movimento sindical pode existir; isso aconteceu somente quando havia um conjunto de regramentos jurídicos que reconheciam trabalhadores e patrões como portadores de direitos iguais. Para o autor, nos modos de produção anteriores ao capitalismo, as revoltas dos produtores diretos contra as condições de exploração do seu trabalho aconteciam de maneira sazonal, por meio de ações abruptas de revolta ou insurreição. O capitalismo criou as condições para a existência do sindicalismo na medida em que: 1) ampliou o nível de desenvolvimento e socialização das forças produtivas - o que, por si só, já tem um papel agregador dos produtores diretos; 2) suprimiu a subordinação pessoal formal do produtor direto ao proprietário dos meios de produção por meio de uma legislação que reconhece uma igualdade, ainda que formal, de ambos perante a lei; 3) abriu a possibilidade de participação de indivíduos provindos da classe dos produtores diretos no aparelho de Estado.

As duas últimas características pertencem ao campo da superestrutura jurídico-política e são fundamentais e nosso foco será na segunda. Em todos os modos de produção anteriores ao capitalismo, qualquer tipo de luta implicava em uma contraposição direta e aberta ao próprio modo de produção. Donos dos meios de produção no escravismo antigo, no feudalismo e no escravismo moderno não poderiam negociar com os produtores diretos - e, historicamente, isso aconteceu de maneira muito isolada - sob o risco de reconhecer neles a contraposição direta àquilo que garantia seu lugar de classe dominante. Para que uma organização de tipo sindical pudesse existir, o lado patronal precisava estar aberto, ainda que a contragosto, a negociar. Reivindicar significa 
afirmar-se como sujeito de direitos, o que era vedado aos trabalhadores em modos de produção anteriores. Apenas no ordenamento jurídico-político de tipo capitalista, uma organização perene dos produtores diretos, tal como é o sindicalismo, pode não representar, a princípio, um ataque ao próprio modo de produção. A reposta das classes dominantes às organizações e ações dos produtores diretos, antes do advento do capitalismo, só poderia ser, via de regra, a repressão; a negociação passou a ser padrão apenas com os direitos civis e políticos conquistados sob o capitalismo. Para Boito Jr. (2007), a relação contratual de assalariamento de tipo capitalista, por um lado, individualiza a relação de trabalho e, por isso, coloca obstáculos à organização dos trabalhadores. Por outro lado, igualmente estimula a negociação em torno de ganhos e condições de trabalho, ou seja, a constituição de agentes coletivos, brecha na qual nasce e atua o movimento sindical.

Outro exemplo de análise em que o aspecto jurídico-político é entendido como central para a compreensão da dinâmica própria dos conflitos em sociedades capitalistas podemos encontrar em Saes (2003). Naquele texto, o autor discute a dinâmica de criação de direitos civis, políticos e sociais por meio de um dispositivo teórico alternativo ao modelo liberal tal como apresentando por Marshall (1967). Ao não considerar a postura distinta das classes dominante e dominada em relação aos direitos, a tradição liberal pressupõe um caráter geral evolutivo da cidadania: a conformação de direitos civis (liberdade individual, de celebrar contratos, preservar propriedade e livre movimentação) levaria aos direitos políticos (prerrogativa de participar do poder político) que, por sua vez, seriam a base para a conquista de direitos sociais (acesso a um mínimo de bem-estar material). Porém, como demonstra o autor, a postura das classes dominantes e do topo da burocracia estatal em relação a esse processo é distinta daquela das classes dominadas. Enquanto as primeiras tendem, no mínimo, a ser estagnacionistas e, no máximo, regressi- vas, as classes dominadas tendem a ter uma postura dinâmica e progressiva. Isso significa, na prática concreta, que nem todos os direitos, uma vez implantados, são irreversíveis.

Como essas bases teóricas informam nossa definição e análise da terceirização? Em primeiro lugar, se a negociação dos termos da venda da força de trabalho entre partes juridicamente equivalentes é, por um lado, uma dimensão estrutural das relações capitalista de trabalho, por outro, isso não implica em um modo único de enquadramento das partes envolvidas. A ação do movimento sindical, ao forçar a imposição de condições coletivas mínimas de contrato em determinada empresa ou setor, impõe um primeiro recuo ao interesse do empregador em individualizar as relações com os empregados. Um segundo tipo de recuo é exigido por legislações que, ao admitirem princípios como o da hipossuficiência do trabalhador, ampliam em nível geral os parâmetros mínimos de venda da força de trabalho para contratos formais (como na CLT, no Brasil).

Ocorre que, na prática concreta, tanto o movimento sindical quanto legislações trabalhistas exigem algum nível de reconhecimento e pressão sobre a figura do empregador real, ou seja, o ente jurídico ao qual são feitas as exigências do contrato. A estratégia empresarial da terceirização, embora possa preservar as regras vigentes de contratos de trabalho formais (terceirização não é sinônimo de informalidade, embora frequentemente contribua para ela, em especial na terceirização em cascata), promove um aparente apagamento dos agentes que, de fato, decidem sobre o uso de capital e sobre o controle do processo de trabalho. Assim, a existência de uma empresa interposta possibilita que o campo da batalha por direitos existentes nas relações trabalhistas recue, ainda que parcialmente, ao campo das negociações comerciais entre empresas, o que explica o vínculo necessário, atestado por ampla literatura na área, entre terceirização e precarização do trabalho. ${ }^{5}$

${ }^{5}$ Marcolino (2019), em balanço de todos os estudos de 


\section{PRINCIPAIS ACONTECIMENTOS JURÍDICO-POLÍTICOS ASSOCIA- DOS À TERCEIRIZAÇÃO PÓS 2012}

Nesta seção analisaremos os principais processos jurídico-políticos ocorridos no período pós 2012 no Brasil: os julgamentos que tinham por objeto o alcance da terceirização no âmbito do Supremo Tribunal Federal (STF) em paralelo à aprovação das Leis 13.429 (lei do trabalho temporário e 13.467 (Reforma Trabalhista) em 2017. Nosso objetivo é refletir, à luz dessas mudanças, se a prova dos fatos permite ou não afirmar que nossa definição de terceirização se mostrou correta e operativa.

Como vimos, na ocasião da publicação do texto em que propusemos nossa definição de terceirização, no ano de 2012, já estava instalado no país debates e lutas em torno de uma Proposta de Lei de número 4330, do ano de 2004, do então deputado Sandro Mabel - pertencente ao Partido do Movimento Democrático Brasileiro, hoje apenas Movimento Democrático Brasileiro, MDB -, rico empresário do ramo alimentício do estado de Goiás. Em 2011, o Congresso Nacional tinha retomado a discussão da PL4330 após ter sido retirado de pauta durante o governo de Lula da Silva. Aliás, a história desse PL é longa: a cada legislatura ele voltava ao debate para ser arquivado mais tarde. De qualquer forma, o PL 4330, que recebeu uma proposta de texto substitutivo de autoria ¿ี do deputado Roberto Santiago (Partido Social స. Democrático/SP), liberava a terceirização de \% maneira praticamente irrestrita, findando com 屯 a distinção entre atividades-fim e atividadesจุ -meio de uma empresa - distinção legal que ¿. servia de apoio jurídico para trabalhadores e Æீ operadores do direito para combater a terceirização e seus efeitos de precarização do trabalho - bem como estabelecia como possibilidade a subcontratação em forma de terceirização

caso sobre terceirização produzidos entre os anos de 1995 e 2016 em forma de teses de doutorado e dissertações de mestrado no Brasil, conclui que não há exceção reconhecida para a assertiva de que a terceirização implica em precarização das condições de trabalho e de contrato de emprego. de serviço especializado de qualquer natureza. Pois bem, em 2015, o PL 4330 foi colocado em votação em regime de urgência pela presidência da Câmara dos Deputados ${ }^{6}$. Ainda sob o governo de Dilma Rousseff, mas já sob os efeitos do desgaste político que ela vinha sofrendo, o movimento sindical convocou três jornadas de luta cujo mote era a denúncia do PL, com manifestações massivas e paralisações de algumas categorias sindicalmente importantes em todas elas, tais como metalúrgicos e trabalhadores de transportes públicos (Marcelino e Galvão, 2020). ${ }^{7}$ Aprovado na Câmara dos Deputados, o PL foi encaminhado para o Senado Federal e lá foi "esquecido" até o tema da terceirização voltar à tona via um outro projeto de lei, o PL4302, cujo objeto, a princípio, era o trabalho temporário.

Toda a mobilização dos trabalhadores contra a aprovação do PL4330 foi atropelada de maneira fragorosa. Se o objetivo do antigo PL4330 era tornar a regulamentação da terceirização completamente permissiva, tal objetivo foi atingido sem que houvesse a necessidade do desgaste político da discussão de um projeto de lei específico sobre o tema. Em 31 de março de 2017, sete meses depois de consumado o golpe em Dilma Rousseff, o governo do Michel Temer aprovou, a partir do PL4302,

${ }^{6}$ Destacamos que, embora esse fosse um projeto já descartado durante as gestões anteriores de Lula e Dilma, a colocação em pauta do PL4330 não foi um "raio em céu azul”. Dilma já havia escalado um nome forte do mercado como Ministro da Fazenda, Joaquim Lévy, e vinha propondo medidas prejudiciais aos direitos dos trabalhadores. Entendemos, inclusive, que: “quando, após a reeleição, Dilma priorizou as medidas neoliberais, sua base de apoio se esgarçou. $\mathrm{O}$ ajuste fiscal e as medidas provisórias que restringiram o acesso ao auxílio-doença, ao recebimento de pensão pelo dependente em caso de morte do segurado (MP 664/2015), ao seguro-desemprego e ao abono salarial (MP 665/2015) geraram insatisfação entre os setores sindicais aliados do governo e lhe custaram a perda de uma parcela significativa de apoio popular" (Marcelino e Galvão, 2020, p. 160).

${ }^{7}$ Segundo Marcelino e Galvão (2020, p. 164): "As manifestações foram convocadas por quase todas as centrais sindicais atuantes (...). A Força Sindical foi a única ausente dos protestos. Retomando, em parte, os argumentos favoráveis à flexibilização de direitos que marcara seu posicionamento nos anos 1990, essa central ficou isolada na defesa do projeto. Mas, diante da expressiva reação das ruas e da oposição das instituições de regulação do trabalho (Anamatra, Ministério Público do Trabalho), até mesmo a Força Sindical começou a subscrever críticas a ele. Para mais detalhes sobre a atuação das centrais diante das propostas de regulamentação da terceirização ver: Marcelino e Galvão, 2020. 
a Lei $13.429,{ }^{8}$ uma lei sobre o trabalho temporário que alterou dispositivos da Lei 6.019 de 1974. Entre os pontos que a nova lei alterou, abriu-se a possibilidade de adoção da terceirização de maneira irrestrita, em qualquer setor das empresas. Assim, um projeto que tratava, inicialmente, da possibilidade de ampliação do uso de trabalho temporário resultou em uma lei que modificou a legislação que regulamentava a intermediação de força de trabalho. A modificação foi chancelada de forma inequívoca, meses depois, pela Reforma Trabalhista, instituída pela Lei 13.467.

Foi sempre isso que esteve em jogo: a possibilidade de haver duas relações jurídicas diferentes regulando de forma ampla o processo e a contratação de trabalho: uma empresa, a tomadora, que estabelece com empresas terceiras um contrato de natureza comercial ou civil para a prestação de um serviço, e empresas terceiras, aquelas cujos contratos da outra ponta, com os trabalhadores, são contratos de natureza trabalhista. Por isso, apenas permitir a terceirização não era suficiente para a diminuição global dos custos com a força de trabalho; era preciso também promover uma reforma trabalhista, era preciso rebaixar, de maneira geral, esses custos tanto para empresas tomadoras - com a possibilidade de terceirização irrestrita e com a diminuição de direitos dos seus próprios empregados - quanto para empresas terceirizadas, cujo gasto com direitos trabalhistas pôde diminuir sensivelmente. Isso sem mesmo contar com outra possibilidade dada pela Lei 13.429: a quarteirização ou terceirização em cascata. Com ela, qualquer empresa terceirizada pode, também, se tornar uma contratante, refazendo o caminho de redução de custos com a força de trabalho e de externalização dos conflitos trabalhistas que a primeira empresa tomadora percorreu.

No texto de 2012, apontamos que a literatura da área de Direito voltada para a assistência e orientação jurídicas das empresas ${ }^{8}$ O conteúdo completo da lei pode ser acessado em: http://
www.normaslegais.com.br/legislacao/lei-13429-2017.htm já se movimentava de modo a questionar os limites objetivos da distinção atividade-meio e atividade-fim, considerando-as muito maleáveis. Já naquele período, a preocupação fundamental das consultorias jurídicas era alertar as empresas sobre os riscos da caracterização de vínculo trabalhista entre a empresa tomadora e trabalhadores terceirizados. Pois bem, mesmo após a aprovação das Leis 13.429 e 13.467, a preocupação subsiste, ainda que bastante reduzida, dada a posição adotada pelo STF em recusar o critério de atividade-fim como limitante da terceirização. O risco de haver caracterização de relação de emprego entre a empresa principal, a tomadora, e o trabalhador terceirizado ainda existe quando, alertam os advogados especializados: a) ocorre a demissão de funcionários para imediata recontratação deles transformados em Pessoa Jurídica (PJ) - é preciso respeitar o tempo de 18 meses de intervalo; b) quando a empresa tomadora quer terceirizar áreas inteiras e quer manter alguns de seus ex-funcionários como empregados da empresa terceirizada - expediente que é possível desde que se respeite a mesma carência de 18 meses entre a demissão e volta do trabalhador na condição de terceirizado; e c) quando há subordinação direta dos trabalhadores da empresa subcontratada à chefia da contratante. ${ }^{9}$

Vale a pena voltarmos a um aspecto da definição que propomos em 2012, a saber, o objetivo de formulá-la de maneira "rigorosa do ponto de vista analítico e útil do ponto de vista político". Distantes, portanto, de um modelo positivista, em que a objetividade do conhecimento viria necessariamente acompanhada da neutralidade axiológica, reconhecíamos que a forma de conceituar o fenômeno tornava-o mais ou menos operativo para as posições políticas na sociedade e no corpo burocrático do Estado atentas à manutenção dos direitos sociais do trabalho. Nesse sentido, as abordagens da terceirização que admitiam, direta ou

9 Disponível em: https://sindtrr.com.br/apos-decisao-do-supremo-empresas-confundem-terceirizados-com-pjs/ Acesso em 13/06/2021. 
indiretamente, a dimensão relativa à especialização técnica ou à acentuação da divisão do trabalho - como vimos, orientandas pela ótica de produção de valores de uso, e não da valorização do valor - abriam, de forma consciente ou não, as portas para discursos fatalistas e tecnicistas no interior dos quais a externalização dos conflitos viabilizada por essa forma de contratação específica (por empresa interposta) era, no mínimo, vista como consequência negativa inevitável de um processo irreversível. No máximo, a estratégia passava a ser sinônimo de eficiência econômica e bem-estar da sociedade.

As discussões realizadas pelos ministros do STF expressam de maneira emblemática a forma pela qual as ideias, operando como forças sociais, transformam-se em normas e dispositivos legais. Os debates são analisados detalhadamente pelos trabalhos de Coutinho (2021); Biavaschi, Droppa e Alves (2021) e Dutra e Lopes (2021), os quais abarcam os diferentes processos em que o STF lidou com o tema da terceirização e, ao fim, legitimou a sua ampliação irrestrita. Gostaríamos de chamar a atenção para alguns aspectos levantados por esses trabalhos.

O primeiro é o de que, até 2017, a recusa dos termos estabelecidos pela Súmula 331 do TST girava em torno do caráter inevitável, de fato consumado, da terceirização. Coutinho (2021) observa uma mudança de ênfase ¿ี a partir de então, na medida em que os voi tos da maioria do plenário do STF começam $\stackrel{\sim}{0}$ a priorizar as exigências impostas pela busca ¿े de eficiência e "modernização" das relações de $\stackrel{9}{7}$ trabalho, momento em que a defesa da livre $\dot{2}$ iniciativa e da liberdade econômica alcançam ले o status de princípios fundamentais e inques-

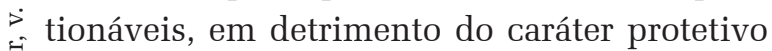
da legislação trabalhista.

Esta posição atinge sua maior radicalização na argumentação do Ministro Gilmar Mendes por ocasião do julgamento da Ação Direta de Inconstitucionalidade (ADI) 5965 em 2020, cujo fundamento reivindica o mote ne- oliberal básico: os direitos do trabalho seriam entraves do direito ao trabalho. A sustentação inicia-se com a comum diferenciação entre o modelo fordista centralizado e internalizado e um novo modelo de produção descentralizado e externalizado; para o ministro, seriam mudanças provocadas por "revoluções culturais". Emblematicamente, Mendes irá encontrar no sociólogo e filósofo polonês Zigmunt Bauman o nome para a coisa que busca definir: viveríamos na "fase líquida da modernidade". Como não apenas o mercado, mas também a própria sociedade teria mudado para essa fase em que "tudo se decompõe e se derrete", não seria possível conceber que o modelo de Direito do Trabalho da primeira metade do século XX fosse compatível com as novas demandas sociais. A permanência desse modelo causaria disfuncionalidade, pois as empresas precisariam arcar com "custos que extrapolam a lógica do mercado em si mesma". Nessa abordagem, também perderiam a legitimidade os limites até aqui impostos à terceirização. Recuperando parte do parecer da Comissão de Assuntos Econômicos do Senado referente à Lei da Reforma Trabalhista, Mendes insere em sua decisão a definição proposta pela comissão: "a terceirização é decorrente da própria especialização do trabalho, tendência que nos últimos séculos permitiu que as sociedades se desenvolvessem e melhorassem a vida das pessoas.". ${ }^{10} \mathrm{Na}$ sequência, Mendes recorre às obras dos liberais Roberto Campos e Ayn Rand para sustentar a superioridade também moral dos princípios de livre mercado.

Constituiu-se, assim, a hegemonia, no STF, de uma noção de terceirização como equivalente de eficiência econômica, o que correspondia aos interesses dos empregadores. Já as teses vencidas, ainda que apontassem para o problema mais amplo de mudanças na divisão do trabalho no capitalismo contemporâneo, buscaram se contrapor à maioria justamente

${ }^{10}$ Voto do Ministro Gilmar Mendes em relação à Ação Direta De Inconstitucionalidade 5.695. Página 12. Disponível em: https://redir.stf.jus.br/paginadorpub/paginador.jsp?docTP=TP\&docID=754326287 Acesso em: 20/06/2021. 
ao considerar como tendo validade empírica mais robusta o conjunto extenso de pesquisas que apontava a precarização do trabalho como objetivo último da terceirização. Foi neste contexto em que a definição que propusemos em 2012 mostrou-se relevante para a fundamentação conceitual das posições que enfrentavam a virada neoliberal em curso. Nos votos relativos aos julgamentos dos Recursos Extraordinários 760.931/2017 e 958.252/2018 (Biavaschi, Droppa e Alves, 2021; Dutra e Lopes, 2021), a ministra Rosa Weber destacou a definição por nós sugerida, inserindo-a, a partir de uma leitura muito correta do nosso texto, em uma problemática "centrada nos impactos da terceirização em relação à exploração da força de trabalho". ${ }^{11} \mathrm{~A}$ hegemonia neoliberal que avança sobre a regulação do trabalho não altera apenas a jurisprudência até aqui existente sobre terceirização que, a despeito de seu limites, oferecia ainda um quadro normativo capaz de impor limites a essa forma de contratação (Biavaschi, Droppa e Alves, 2021). Esse processo tem levado ao completo abandono de princípios fundamentais da própria tipificação de vínculo de emprego em geral. $\mathrm{O}$ citado voto de Mendes alude à próxima fase, já em curso, das disputas trabalhistas, agora trazidas à tona pela proliferação de empresas cujo modelo negócio são sustentados pela contratação de trabalho supostamente autônomo em plataformas informacionais.

Para admitirmos que os ares socioeconômicos são completamente diversos daqueles em que se assentaram as bases principiológicas do Direito do Trabalho, basta observar que a maior empresa de transportes do mundo não tem um carro sequer, e a maior empresa de hospedagem do mundo também não dispõe de um único apartamento. Refiro-me aos paradigmáticos Uber e Air B\&B [sic], ambos fundados em economia colaborativa e na descentralização da atividade econômica entre diversos agentes mercadológicos. ${ }^{12}$

11 Inteiro Teor do Acórdão - Recurso Extraordinário 760.931. Página 11. Disponível em: https://redir.stf. jus.br/paginadorpub/paginador.jsp?doc TP $=$ TP\&doCID =13589144 Acesso em: 20/06/2021.

${ }^{12}$ Voto do Ministro Gilmar Mendes em relação à Ação Direta De Inconstitucionalidade 5.695, p. 10. Disponível em: https://redir.stf.jus.br/paginadorpub/paginador.jsp?doc$\mathrm{TP}=\mathrm{TP} \& d o c I D=754326287$ Acesso em: 20/06/2021.
A ideia de que empresas como a Uber são expressões de economias colaborativas e descentralizadas mistifica e oculta o sofisticado processo de controle do trabalho viabilizado pela programação algorítmica dessas plataformas e a enorme centralização de poder e informações por essas empresas (Abílio, 2020). Elas não precisam deter a propriedade legal de carros e motos, que permanece vinculada ao trabalhador, porque já têm a posse efetiva dos instrumentos de trabalho adequados a seus fins (Filgueiras e Cavalcante, 2020). Porém, a maneira mais frequente pela qual o trabalho tem sido contratado por essas plataformas não se efetiva por terceirizações, já que não há empresas interposta. A relação é direta entre empresas e trabalhadores; só que esses são vistos e tidos como "parceiros" autônomos. É possível, à luz do que até aqui discutimos e publicamos sobre o tema, projetar tendências futuras. Vejamos.

Embora o Poder Judiciário apresente posições majoritárias que correspondem à hegemonia do pensamento e das políticas neoliberais - ou seja, não identifique vínculo empregatício entre trabalhadores e empresas donas das plataformas -, as pressões objetivas por melhorias das condições de trabalho e remuneração são inevitáveis e, aos poucos, ganham formas coletivas de resistência. Pressionados por esse impasse, já existem medidas legislativas que buscam criar um quadro de proteção legal mínimo a trabalhadores em plataformas, ainda que em condições rebaixadas se comparadas à CLT, por considerá-los "nem empregados diretos, nem autônomos". ${ }^{13}$

O acompanhamento que temos feito da posição das empresas até aqui revela a correção da definição que propusemos de terceirização. Algumas empresas participaram ativamente do processo por meio de consultorias e lobby legislativos. Porém, recentemente, colhemos indícios de uma reorientação estratégica: em

13 Como exemplo, o PL3748/2020 da Deputada Federal Tábata Amaral (PDT-SP). Disponível em: https:/www.camara.leg.br/proposicoesWeb/fichadetramitacao?idProposicao=2257468 Acesso em: 20/06/2021. 
vez de apostar nesse enquadramento rebaixado em relação à CLT, irão fortalecer a contratação de trabalho por empresas interpostas. Um caso concreto é a modalidade chamada Operadores Logísticos (OL) do IFood, maior aplicativo de entrega de comida no país. Nessa modalidade, busca-se a garantia de fornecimento de força de trabalho em períodos pré-determinados por meio da contratação de intermediários, os OLs, que se tornam responsáveis por controlar a jornada e repassar a remuneração aos entregadores a eles vinculados. Em suma, a terceirização volta a ocupar o lugar a que foi destinada nessa estratégia: contratar trabalhadores por empresas interposta com o objetivo último de reduzir custos com força de trabalho e externalizar conflitos trabalhistas.

\section{CONSIDERAÇÕES FINAIS}

A luta contra a terceirização, já antes difícil, tornou-se muito pior desde a promulgação das Leis 13.429 e 13.467 e as recentes decisões do STF sobre o tema. Cada vez é mais difícil para sindicatos e trabalhadores terem a memória de como foi o processo de terceirização dentro das empresas (públicas e privadas) e dos serviços públicos, quais setores foram terceirizados e qual é a medida exata das perdas sofridas pela força de trabalho. Em breve, a pergunta "O que perdemos com a terceirizaస్ ção?" nem fará mais sentido em muitos locais - de trabalho, pois, em se podendo terceirizar absolutamente qualquer setor de uma empre¿ sa ou qualquer área do serviço público, muitos $\stackrel{9}{7}$ deles já nascerão nesse regime específico de $\dot{\sim}$ subcontratação que é a terceirização.

Quais nos parecem ser, então, as saídas possíveis para a luta dos trabalhadores e das trabalhadoras?

É preciso, neste momento, enfatizar a dimensão normativa que o problema suscita. Parece-nos, cada vez mais, que o movimento dos trabalhadores organizado deve ter claro quais são os parâmetros das relações e condi- ções de trabalho e emprego desejáveis ou, no mínimo, aceitáveis. A Organização Internacional do Trabalho (OIT), com a agenda do chamado "trabalho decente", indica um caminho e critérios nos quais se apoiar:

(...) a) respeito às normas internacionais do trabalho, em especial aos princípios e direitos fundamentais do trabalho - liberdade sindical e reconhecimento efetivo do direito de negociação coletiva; eliminação de todas as formas de trabalho forçado; abolição efetiva do trabalho infantil; eliminação de todas as formas de discriminação em matéria de emprego e ocupação; b) promoção do emprego de qualidade; c) extensão da proteção social; d) diálogo social (Dieese, 2015, p. 13).

O movimento sindical brasileiro, por meio do Dieese, oferece uma ferramenta importante para estabelecer, com mais detalhes, o item $\mathrm{b}$ da agenda do trabalho decente da OIT. Por causa do Dieese, sabemos, periodicamente, qual deveria ser o valor de um salário-mínimo que cumprisse o objetivo constitucional ${ }^{14}$ de manter um trabalhador e sua família (dois adultos e dois filhos menores de 18 anos). Sabemos que hoje, junho de 2021, por exemplo, o salário-mínimo nacional é quase cinco vezes menor do que o necessário. ${ }^{15}$ Pois bem, para o movimento sindical e dos trabalhadores brasileiros, em que consiste o emprego aceitável e desejável? Aquele que pague o salário-mínimo calculado pelo Dieese, ainda que ele considere, a princípio, que apenas "o pai da família” trabalhe? Aquele emprego que seja regido por um contrato de trabalho por tempo indeterminado? Aquele que não seja turno parcial a não ser por opção do trabalhador ou da trabalhadora?

14 "A Constituição de 1946 introduziu mudança no sentido de determinar que o SM deveria atender também às necessidades da família do trabalhador, caracterizando-o como salário-mínimo familiar. A Constituição de 1988 renovou esse direito a todos os trabalhadores urbanos e rurais, definindo no Artigo $7^{\circ}$, Inciso IV: "salário mínimo, fixado em lei, nacionalmente unificado, capaz de atender a suas [dos trabalhadores] necessidades vitais básicas e às de sua família com moradia, alimentação, educação, saúde, lazer, vestuário, higiene, transporte e previdência social, com reajustes periódicos que lhe preservem o poder aquisitivo, sendo vedada sua vinculação para qualquer fim" (Dieese, 2019, p. 2).

15 Disponível em: https://www.cnnbrasil.com.br/business/2021/06/08/salario-minimo-ideal-subiu-para-r-5351-11-em-maio-diz-dieese Acesso em: 19/06/2021. 
E como são as condições de trabalho mínimas aceitáveis? Um trabalho que permita tempo de lazer? Um trabalho livre de assédio moral ou sexual? Um trabalho que garanta equidade de gênero e raça/etnia?

Pois bem, sejam quais forem os parâmetros exatos para as condições de contrato e de trabalho que podemos entender como aceitáveis, o quadro que eles formam não é, ainda hoje, organizado e defendido de forma sistemática e ampla. ${ }^{16}$ É certo que, em alguma medida, esses temas aparecem nas pautas iniciais de negociações coletivas. Contudo, não é esse o quadro que tem alimentado o imaginário social sobre o trabalho e as lutas em torno de suas condições ${ }^{17}$. Se assim o fosse, a terceirização, enquanto forma de redução de custos com a força de trabalho, não teria a força que tem. Talvez o próprio fato de ser ou não um trabalhador ou uma trabalhadora terceirizado ou terceirizada perderia a importância material e simbólica que a condição tem hoje.

É inegável que esse imaginário social sobre o "trabalho decente", o trabalho que queremos e aceitamos, se fragiliza com a materialidade da ofensiva neoliberal e pela força ideológica da desconstrução da própria identidade de ser trabalhador - substituída pela de empreendedor e autônomo. Aos novos nomes, mudanças substantivas de sentido se vinculam: quanto maior o constrangimento estrutural do mercado, maior seria a "agência" do indivíduo e seu mérito. Reconstruir um sentido efetivo de dignidade vinculada ao trabalho é, assim, um desafio crucial do nosso tempo.

Recebido para publicação em 20 de junho de 2021 Aceito em 12 de novembro de 2021

${ }^{16}$ Uma tentativa, ainda que preliminar, foi a proposta, em 2018, de um Estatuto do Trabalho, apresentada pelo Senador Paulo Paim (PT-RS) em resposta à aprovação da Reforma Trabalhista (https://www12.senado.leg.br/radio/1/noticia/2018/05/10/paulo-paim-apresenta-estatuto-do-trabalho).

${ }^{17} \mathrm{E}$ a situação se agrava com a estrutura sindical brasileira, que permite a multiplicação de sindicatos de base e uma corrida pela obtenção da carta sindical por cada "nova categoria" criada com a permissividade irrestrita da terceirização (Boito, 1992; Marcelino, 2015).

\section{REFERÊNCIAS}

ABÍLIO, L. C. Uberização: a era do trabalhador just-intime? Estudos Avançados, 34 (98), 2020, p. 111-126.

BIAVASCHI, M. B.; DROPPA, A.; ALVES, A. C. A terceirização no contexto da reforma trabalhista e as decisões judiciais: limites, contradições e possibilidades. In: DUTRA, R.; MACHADO, S. (Orgs.). O Supremo e a Reforma Trabalhista: a construção jurisprudencial da Reforma Trabalhista de 2017 pelo Supremo Tribunal Federal. Porto Alegre, Fi, 2021, p. 67-99.

BOITO JR, A. Pré capitalismo, capitalismo e resistência dos trabalhadores: elementos para uma teoria da ação sindical. In: Estado, política e classes sociais. Şão Paulo: Editora da Unesp, 2007, pp. 155-187.

BOITO JR., A. Reforma e Crise política no Brasil: os conflitos de classe nos governos do PT. Campinas e São Paulo: Editora Unicamp e Editora Unesp, 2018, 331 p.

BOITO JR. A. Sindicalismo de Estado no Brasil. Campinas e São Paulo, Unicamp e Hucitec, 1992, 316 p.

COUTINHO, A. R. Terceirização no setor público vista pela ADC 16, ADI 1923 e tema 246 em repercussão geral: em pauta o STF. In: DUTRA, R.; MACHADO, S. (Orgs.). O Supremo e a Reforma Trabalhista: a construç̃o jurisprudencial da Reforma Trabalhista de 2017 pelo Supremo Tribunal Federal. Porto Alegre, Fi, 2021, p. 31-66.

DEPARTAMENTO INTERSINDICAL DE ESTATÍSTICAS E ESTUDOS SOCIOECONÔMICOS - (Dieese). Indicadores da agenda do trabalho decente. 2015, 116 p.

DEPARTAMENTO INTERSINDICAL DE ESTATÍSTICAS E ESTUDOS SOCIOECONÔMICOS (Dieese). SalárioMínimo: pela manutenção da valorização! Nota Técnica $\mathrm{n}^{\circ} 218,2020,12 \mathrm{p}$

DUTRA, R. e LOPES, J. G. P. O STF e a terceirização: o julgamento da ADI 5685 e da ADI 5695 quanto à constitucionalidade da terceirização irrestrita (Lei 13.429/2017 e Lei 13.467/2017). In: DUTRA, R. MACHADO, S. (Orgs.). O Supremo e a Reforma Trabalhista: a construção jurisprudencial da Reforma Trabalhista de 2017 pelo Supremo Tribunal Federal. Porto Alegre, Fi, 2021, p. 100-126.

FAGNANI, E. Previdência: o debate desonesto. São Paulo: Contracorrente, 2019, 255 p.

FILGUEIRAS, V.; CAVALCANTE, S. What has changed: a new farewell to the working class? Revista Brasileira de Ciências Sociais, v. 35, n. 102, 2020, p. 1-22.

GALVÃO, A.et.al. Contribuição Crítica à Reforma Trabalhista, Centro de Estudos Sindicais e Economia do Trabalho (Cesit), 2017, $70 \mathrm{p}$

MARCELINO, P.; CAVALCANTE, S. Por uma definição de terceirização, Caderno CRH, v.25 n. 65, 2012, pp. 331-346.

MARCELINO, P.; GALVÃO, A. O sindicalismo brasileiro diante da ofensiva neoliberal restauradora. Tempo Social, v. 32 , n. 1,2020 , p. 157-182.

MARCELINO, P. Trabalhadores terceirizados e luto sindical. Curitiba, Appris, 2015, 310 p.

MARCOLINO, A. M. Balanço da produção academia brasileira sobre as condições e relações de trabalho dos terceirizados. 2019, 242 p. Dissertação (Mestrado em Sociologia) - Programa de Pós-Graduação em Sociologia da Universidade de São Paulo.

MARSHALL, T. H. (1967). Cidadania, Classe Social Status. Rio de Janeiro: Zahar, 1967, 220 p.

MARX, Karl. O Capital. Livro 1, vol. 1. 18 a edição. Rio de Janeiro: Civilização Brasileira, 2001, 574 p. 
MORALES, V. O avanço do retrocesso. Opinião. Folha de São Paulo, 6/02/2010. Disponível em: https://www1.folha. uol.com.br/fsp/opiniao/fz0602201009.htm Acesso em 20.06.2021.

PAULANI, L. Acumulação e rentismo: resgatando a teoria da renda de Marx para pensar o capitalismo contemporâneo. Revista de Economia Política, vol. $36, \mathrm{n}^{\circ} 3$ (144), 2016, p. 514-535.

POULANTZAS, N. Classes sociais no capitalismo hoje. Rio de Janeiro: Zahar, 1978, 370 p.
POULANTZAS, N. Poder político e classes sociais. Campinas: Unicamp, 2019, 368 p.

SAAD FILHO, A. O valor de Marx: economia política para o capitalismo contemporâneo. Campinas: Unicamp, 2011, $216 \mathrm{p}$.

SAES, D. A. M. Cidadania e capitalismo: uma crítica à concepção liberal de cidadania. Crítica Marxista, n.16, 2003, p. 9-38. 


\section{REVISITING A DEFINITION OF OUTSOURCING}

\author{
Sávio Cavalcante \\ Paula Marcelino
}

In 2012 we suggest a definition for outsourcing as a workers' hiring process done through an intermediary company, whose ultimate objective is to reduce costs in relation with labor power and/or the externalization of labor conflicts. In this article, we intend to argue the validity of this definition in light of subsequent events in Brazil, namely: cases judged by the Federal Supreme Court (STF) since then and the laws enacted in 2017 (Laws 13.429 and 13.467) that allowed all forms of outsourcing. We will clarify the theorical basis of the definition and argue that it remains valid and important for empirical analysis. We use document analysis (texts produced and published in commercial, trade union and independent press and Supreme Court documents) and literature review.

KEY WORDS: Outsourcing. Subcontracting. Labor. Brazil.

\section{REVISER UNE DÉFINITION DE SOUS TRAITANCE}

\author{
Sávio Cavalcante \\ Paula Marcelino
}

En 2012, nous avons défendu une définition du phénomène: la sous-traitance est tout processus d'embauche de travailleurs par une entreprise intermédiaire, dont l'objectif ultime est la réduction des coûts avec la main-d'œuvre et/ou l'externalisation des conflits du travail. Avec cet article, nous entendons affirmer la validité de cette définition à la lumière des événements juridicopolitiques localisés au Brésil et qui sont postérieurs à celui-lá, à savoir : les processus jugés par la Cour suprême (STF) à ce jour et les lois qui ont publié l'externalisation de manière illimitée, promulguée en 2017 (lois 13429 et 13 467). Nous expliquerons également les racines théoriques de notre définition. Nous défendrons la thèse que cette définition reste valable et opérationnelle. La recherche a été menée par analyse documentaire (textes produits et publiés dans la presse commerciale, syndicale et indépendante, documents du Tribunal fédéral et revue bibliographique.

Mots-CLÉs: Outsourcing. Sous-traitance. Travail. Brésil.

Sávio Cavalcante - Professor do Departamento de Sociologia do Instituto de Filosofia e Ciências Humanas (IFCH) da Universidade Estadual de Campinas (Unicamp). Mestre e Doutor em Sociologia pela Unicamp. Integra o Centro de Estudos Marxistas (CEMARX) e o Centro de Sociologia Contemporânea (CSC) do IFCH. É membro do comitê editorial da revista Crítica Marxista. Desenvolve pesquisas nas áreas de Trabalho, Classes Sociais e Teoria Sociológica.

Paula Marcelino - Professora do Departamento de Sociologia da Universidade de São Paulo (USP). Doutora em Ciências Sociais pela Universidade Estadual de Campinas (Unicamp). Integra o Centro de Estudos dos Direitos da Cidadania (Cenedic) da USP. Publicou os seguintes livros: A logística da precarização: terceirização do trabalho na Honda do Brasil (São Paulo, Expressão Popular, 2004), Trabalhadores terceirizados e luta sindical (Curitiba, Appris, 2013) e, em coautoria com Andreia Galvão e Patrícia Vieira Trópia, As bases sociais das novas centrais sindicais brasileiras (Curitiba, Appris, 2015). É membro do comitê editorial da revista Crítica Marxista. 
